FERMHAB-TM-1871

\title{
An Assessment of Alternatives for Replacing Freon 113 in Bench-Type Electrical Circuit Board Cleaning at Fermi National Accelerator Laboratory
}

Kenneth Isakson and Aimee L. Vessell

Fermi National Accelerator Laboratory

P.O. Box 500, Batavia, Illinois 60510

December 1993 


\section{Disclaimer}

This report was prepared as an account of work sponsored by an agency of the United States Government. Neither the United States Government nor any agency thereof, nor any of their employees, makes any warranty, express or implied, or assumes any legal liability or responsibility for the accuracy, completeness, or usefulness of any information, apparatus, product, or process disclosed, or represents that its use would not infringe privately owned rights. Reference herein to any specific commercial product, process, or service by trade name, trademark, manufacturer, or otherwise, does not necessarily constitute or imply its endorsement, recommendation, or favoring by the United States Government or any agency thereof. The views and opinions of authors expressed herein do not necessarily state or reflect those of the United States Government or any agency thereof. 


\title{
An Assessment of Alternatives for Replacing Freon 113 in Bench Type Electrical Circuit Board Cleaning at Fermi National Accelerator Laboratory
}

\author{
Prepared for \\ U.S. Department of Energy \\ Environmental Restoration and Waste Management \\ Office of Waste Management \\ Waste Minimization Division \\ FERMILAB-TM-1871
}

Prepared by

Kenneth Isakson

Aimee L. Vessell

July 1994 


\section{ACKNOWLEDGMENTS}

The authors would like to recognize and thank the following individuals of Fermi

National Accelerator Laboratory who aided this project with their knowledge and skills:

Butch W. Hartman, ES\&H Section

Jefferey L. Hauman, ES\&H Section

Audrey A. Hopper, Accelerator Division/ Safety

Frederick P. Krueger, ES\&H Section

Rene Padilla, Accelerator Division/ RF

Daniel P. Schoo, Research Division/ EE Dept.

Timothy J. Wolf, ES\&H Section 


\section{EXECUTIVE SUMMARY}

Fermilab is presently phasing out all solvents containing Freon-113 (CFC-113) as part of the continuing Waste Minimization Program. These solvents are used primarily in cleaning the flux off of electronic circuit boards after soldering, specifically in bench type work. Title VI (Stratospheric Ozone Protection) of the Clean Air Act mandates a production phase-out for ozone depleting substances (ODSs), like CFC-113, by the year 2000. Our study addresses this issue by evaluating and choosing alternative non-CFC solvents to replace the CFC-113 solvents at Fermilab.

Several potential non-CFC cleaning solvents were tested. The evaluation took place in three parts: controlled experimental evaluation, chemical composition evaluation, and employee performed evaluation. First, we performed a controlled nine-step procedure with the potential solvents where each was evaluated in categories such as cleaning effectiveness, odor, residue, type of output (spray, stream, etc.) and drying time (see Table 2.1). Next, we listed the chemical composition of each solvent (see Table 2.2). We noted which solvents contained HCFCs (hydrochlorofluorocarbons) because they are targeted for phase-out in the future and will be recognized as interim solutions only. Finally, after preliminary testing, five solvents were chosen as the best options. These solvents were sent to be tested by Fermilab employees who use such materials. Their opinions are valuable not only because they are knowledgeable in this field, but also because they will be using the solvents chosen to replace the CFC. 113 solvents.

The results favored two "best alternatives": Safezone Solvent Flux Remover by Miller-Stephenson (a Class II HCFC) and E-Series CFC Free Flux-Off 2000 by Chemtech (a viable, but flammable alternative).

Another possible solution also pursued is the no-clean solder option. This represents the ideal solution since no-clean solder leaves no significant flux residue on the circuit boards and thus requires no further cleaning. In addition, the no or low lead content of these solders was also appealing. One setback, however, is that many different types of solders must be available to insure material compatibility in every case. In our study, we were not able to thoroughly investigate the many types of no-clean solders because of time and financial constraints. The testing that was done, however, showed that no-clean solder was a viable alternative in many cases. Thus, although no-clean solder is not a practical solution for this evaluation, it may prove promising for future use with further study.

We recommend that the chosen solvents be introduced in a timely manner for several reasons. First, phasing out the CFC-113 solvents now will allow Fermilab's Waste Minimization Program to remain on schedule and able to deal with other equally important matters. Second, Fermilab employees who use the cleaning solvents are faced with waning supplies and anxiously await the arrival of the new non-CFC solvents so they can continue their work on schedule. Finally, because CFC-113 has been heavily taxed, the phase-out of this material and the implementation of the new, less expensive non-CFC solvents will be a strong cost-cutting measure at Fermilab. 


\section{LIST OF ACRONYMS}

CFC

CFC-113

$\mathrm{CO} 2$

CRADA

DOD

DOE

HCFC

ODP

ODS

SNAP

VOC
Chlorofluorocarbon

Freon 113

Carbon Dioxide

Cooperative Research and Development Agreement

Department of Defense

Department of Energy

Hydrochlorofluorocarbon

Ozone Depleting Potential

Ozone Depleting Substance

Significant New Alternatives Policy

Volatile Organic Compound 


\section{Table of Contents}

ACKNOWLEDGEMENTS ................................ . . . .

EXECUTIVE SUMMARY . . . . . . . . . . . . . . . . . . . i iii

LIST OF ACRONYMS . . . . . . . . . . . . . . . . . . . . . . . . . . . . . . . . . $\mathbf{v}$

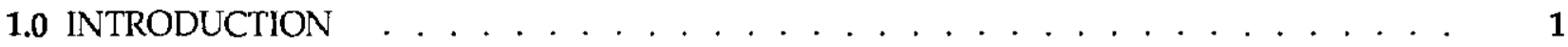

2.0 INVESTIGATIVE PROCEDURES FOR CFC-113 ALTERNATIVES . . . . . . . . . . . . . . . 3

2.1 POTENTIAL CLEANING SOLVENT ALTERNATIVES TO CFC-113
IN BENCH TYPE ELECTRONIC CIRCUIT BOARD CLEANING . . . . . . . . 3

2.1.1 MATERIALS USED . . . . . . . . . . . . . . . . . . . . 3

2.1.2 STEP-BY-STEP PROCEDURE . . . . . . . . . . . . . . . . 3

2.1.3 RESULTS . . . . . . . . . . . . . . . . . . . 6

2.1.3.1 PRELIMINARY RESULTS . . . . . . . . . . . . . 6

2.1.3.2 FURTHER INVESTIGATION _. . . . . . . . . . 7

2.1.4 FUTURE ALTERNATIVES TO HCFCs . . . . . . . . . . . . 9

2.2 NO-CLEAN SOLDERING ALTERNATIVES . . . . . . . . . . . . . . . . . . 10

2.2.1 MATERIALS USED . . . . . . . . . . . . . . . . . . . . 11

2.2.2 PROCEDURE . . . . . . . . . . . . . . . . . . . . . . . 11

2.2.3 RESULTS . . . . . . . . . . . . . . . . . . . . . . . . . 11

3.0 OVERVIEW OF REFERENCES . . . . . . . . . . . . . . . . . . . . . . . . . . . . . . . . . . 13

3.1 INSIGHTS OF SELECTED REFERENCES INTO CLEANING SOLVENT
ALTERNATIVES TO CFC-113 _ . . . . . . 13

3.1.1 An Assessment of Alternatives and Technologies for

Replacing Ozone-Depleting substances at DOE

Facilities - (Battelle) . . . . . . . . . . . . . . . . . . . . 13

3.1.1.1 RECYCLE AND RECOVERY . . . . . . . . . . . . . . . 13

3.1.1.2 THE ROLE OF MIL-SPECS AND

MIL-STANDARDS ............... . . . 14

3.1.2 Evaluation of a No-Clean Soldering Process Designed to

Eliminate the Use of Ozone Depleting Chemicals -

(CRADA) .................. . . 14

3.1.3 Waste Minimization Program Accomplishments Fiscal

Years 1990,91, and 92 . . . . . . . . . . . . . . . . . 15

3.1.4 Eliminating CFC-113 and Methyl Chloroform in Precision Cleaning Operations . . . . . . . . . . . . . . . . . . 15

3.1.5 Solvent Substitution . . . . . . . . . . . . . . . . . . . . 15

3.2 INSIGHTS OF SELECTED REFERENCES INTO THE NO-CLEAN SOLDER

ALTERNATIVE . . . . . . . . . . . . . . . . . . . 16

3.2.1 Evaluation of a No-Clean Soldering Process Designed to

Eliminate the use of Ozone Depleting Chemicals -

(CRADA) ................. 16

3.2.2 Solvent Substitution _. . . . . . . . . . . . . . . . . . . . . . . . . 16

3.2.3 The 1992 International CFC and Halon Alternatives

Conference-Stratospheric Ozone Protection For the 90's . . . . . 17

4.0 CONCLUSIONS \& RECOMMENDATIONS . . . . . . . . . . . . . . . . . . . . . . 19 
APPENDIX A - CATALOG OF DATA FOR CLEANING SOLVENTS TESTED . . . . . . . . 23

APPENDIX B - SELECTED CONTACTS . . . . . . . . . . . . . . . . . . $4 \mathbf{4 1}$

APPENDIX C - TASK DESCRIPTION DOCUMENT . . . . . . . . . . . . . . . . . . 45 


\section{FIGURES}

FIGURE 2.1 Ranking of Four No-Clean Solders . . . . . . . . . . . . . . . . . . . . . 12

TABLES

TABLE 2.1 Solvent Cleaning Results . . . . . . . . . . . . . . . . . . . . . . . . . . 4-5

TABLE 2.2 Cleaning Solvent Chemical Composition . . . . . . . . . . . . . . . . . . . 8 


\subsection{INTRODUCTION}

Freon 113 is a chlorofluorocarbon (CFC-113) widely used in DOE (Department of Energy) facilities as a solvent for cleaning metal parts. It is a good solvent for oils, grease, and specifically rosin soldering flux. It also has high chemical stability, low toxicity, and zero flammability which make CFC-113 the usual cleaning solvent chosen for bench type electronic circuit board cleaning.

Despite these benefits, CFC-113 is being curtailed and will soon be eliminated per Title VI (Stratospheric Ozone Protection) of the Clean Air Act for several reasons. Firstly, CFC-113

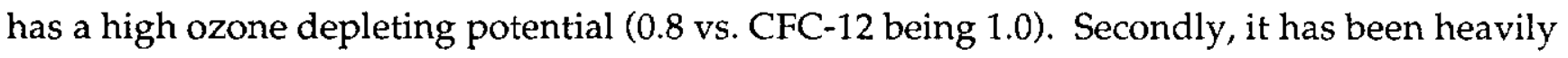
taxed and is thus very expensive. This expense comes into play specifically in bench type electronic circuit board cleaning since solvents are sprayed or wiped on generously. This leads to the use of large and costly volumes of stock in a relatively short time. Thirdly, CFC-113 solvent waste as fugitive emissions is a concern. Although recovery equipment is available, it is not $100 \%$ efficient and still requires the disposal of the waste we wish to minimize. Furthermore, such equipment is not very practical for bench type work. For these reasons, it is necessary to find a substitute for CFC-113.

Our study focuses on finding comparable non-CFC alternatives to the CFC-113 solvents presently used for cleaning the flux off of circuit boards after soldering. Several solvents were evaluated based on cleaning effectiveness and chemical composition. Within the chemical composition evaluation, we noted whether the solvent contained HCFCs

(hydrochlorofluorocarbons). HCFCs have lower, but still significant, ozone depleting potential (ODP) than CFCs do and for this reason are targeted for phase-out some time in the future.

Thus, HCFC solvents, if chosen, should be considered as transitional alternatives only.

The use of no-clean solders was also investigated as an alternative to CFC-113 solvents. Using no-clean solders eliminated the cleaning process altogether and thus would be a simpler, less costly process.

Following the evaluation, a brief overview of pertinent information contained in the references consulted is included. This serves both to support the reasoning behind recommendations made in this study, as well as to provide information and direction that may be helpful in other studies. 


\subsection{INVESTIGATIVE PROCEDURES FOR CFC-113 ALTERNATIVES}

\subsection{POTENTIAL CLEANING SOLVENT ALTERNATIVES TO CFC-113 IN BENCH TYPE ELECTRONIC CIRCUIT BOARD CLEANING}

Most of the soldering work done on circuit boards at Fermilab consists of minor repairs or modifications. As with all soldering work, some clean-up is necessary in order to remove any remaining flux or residue. For bench type work, this clean-up requires a compact but effective process. For this reason, small hand held quantities of effective cleaner such as spray cans or pump sprays are usually best suited for bench type electrical circuit board cleaning. This investigation focuses on the evaluation of several cleaning solvents in order to find the one(s) which best suit the need for an easy to handle and effective cleaner.

\subsubsection{MATERIALS USED}

The following materials were used in the evaluation of the cleaning solvents:

Soldering iron, solder, toothbrushes ( 1 per cleaner), circuit boards, cleaning solvents to be tested, safety glasses with side shields, lab hood, latex gloves, glass microscope slides.

\subsubsection{STEP-BY-STEP PROCEDURE}

- Don safety glasses and latex gloves; turn on lab hood (Note: all work done in lab hood)

- Solder small area of circuit board

- Spray area with cleaning solvent to remove flux

- Note any released odor

- Scrub area with toothbrush

- Spray area again if necessary

- Visually inspect area for cleanliness (fair, good, or excellent), residue, and effect on board (any apparent degradation of circuit board itself)

- Spray glass microscope slide with solvent to check for residue.

- Record findings on data sheet (see Table 2.1) 


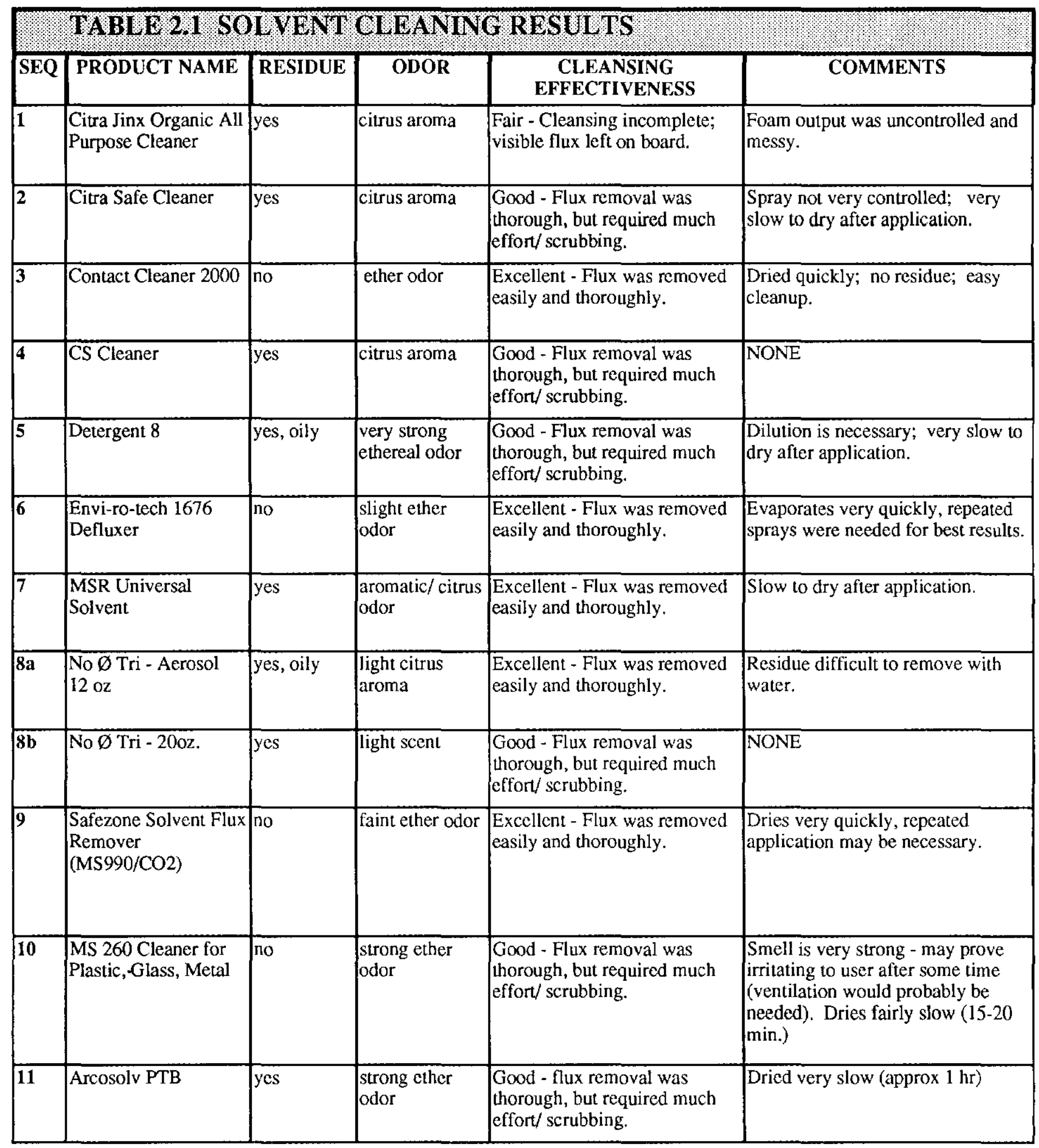




\begin{tabular}{|l|l|l|l|l|l|}
\hline $\mathbf{1 2}$ & Hexyl Acetate & yes & $\begin{array}{l}\text { sweet smelling } \\
\text { - like banana oil }\end{array}$ & $\begin{array}{l}\text { Good - Flux removal was } \\
\text { thorough, but required much } \\
\text { effor/ scrubbing. }\end{array}$ & $\begin{array}{l}\text { Smell is potent - may prove } \\
\text { irritating to user after some time. }\end{array}$ \\
\hline $\mathbf{1 3}$ & Isopropyl Alcohol & yes & $\begin{array}{l}\text { slight alcohol } \\
\text { odor }\end{array}$ & $\begin{array}{l}\text { Good - Flux removal was } \\
\text { thorough, but required much } \\
\text { effort/ scrubbing. }\end{array}$ & $\begin{array}{l}\text { Dispensing material was awkward } \\
\text { as no propelling device was } \\
\text { available. }\end{array}$ \\
\hline $\mathbf{1 4}$ & $\begin{array}{l}\text { E-Series CFC Free } \\
\text { Flux-Off 2000 }\end{array}$ & yes, slight & $\begin{array}{l}\text { mild } \\
\text { hydrocarbon } \\
\text { odor }\end{array}$ & $\begin{array}{l}\text { Excellent - Flux was removed } \\
\text { easily and thoroughly }\end{array}$ & $\begin{array}{l}\text { Residue apparent was only slight. } \\
\text { Cleaning was above average. } \\
\text { Clearly the best of all solvents } \\
\text { tested yet. (no CFCs) }\end{array}$ \\
\hline $\mathbf{1 5}$ & $\begin{array}{l}\text { E-Series Alcohol } \\
\text { Blend Flux-Off } 2000\end{array}$ & yes & Alcohol odor & $\begin{array}{l}\text { Good - Flux removal was } \\
\text { thorough, but required much } \\
\text { effort/ scrubbing }\end{array}$ & $\begin{array}{l}\text { Pump spray not as effective as } \\
\text { aerosol. }\end{array}$ \\
\hline
\end{tabular}


Note that in all cases the area to be cleaned was treated with cleaning solvent immediately after soldering was completed. This is an important control as the longer the delay in removing the flux after soldering, the more difficult removal becomes. The delay time becomes more of a factor if a significant amount of time has past (a day or more).

Also, as mentioned in the procedure in step 8 , any residue left on the board after cleaning was noted. This residue, if significant enough, is unfavorable as it would require further cleaning. It was recognized that this residue could come from several sources: 1) residue already on the board before cleaning 2) residue from a combination of the board flux and solvent 3 ) residue from the solvent itself. In order to distinguish between these three cases and determine if the residue was in fact caused directly by the solvent, a glass microscope slide was treated. Those solvents that appeared to leave a residue on the circuit board after cleaning were applied to glass slides. If the same residue was left on the slide as well, it was concluded that the solvent itself left the residue. Those solvents that left a residue are noted as such in Table 2.1.

\subsubsection{RESULTS}

The results have been separated into two sections: Preliminary Testing and Further Investigation. These sections separate the conclusions drawn from the data collected by the procedure in section 2.1.2 from the findings of Fermilab employees chosen to test given solvents because of their experience with such bench type circuit board cleaning operations.

\subsubsection{PRELIMINARY TESTING}

The results of this experiment are summarized in Table 2.1 titled "Solvent Cleaning Results". Note that this procedure was a preliminary investigation used to evaluate cleaning effectiveness only. This preliminary work allowed us to eliminate those solvents which did not merit detailed study. Chemical composition was to be considered after the cleaning effectiveness evaluation.

Those solvents that were eliminated immediately by the preliminary testing clearly fell short of the desired and necessary cleaning standards. Specific reasons for elimination are listed in the "cleaning eff" and "comments" columns of Table 2.1. The main reason for discarding these solvents was their inadequate cleaning capabilities (indicated by a listing of only fair or good). Accompanying reasons include messy foam output, difficult to control sprays, significant residue, or long drying times. The long drying times seem typical of many terpenes and some hydrocarbons as supported by comparing the eliminated "long drying time" solvents (see Comments in Table 2.1) and their respective chemical composition in Table 
2.2 titled "Cleaning Solvent Chemical Composition" (Note particularly sequence \#1,2,5,7, and 11. In these cases terpenes and/or hydrocarbons were present.) The use of a heat gun or hair dryer (for non-flammable cases only) may eliminate this slow drying problem, but would obviously add a step to the cleaning process.

The results in Table 2.1 show several solvents labeled "excellent" under cleaning effectiveness. These solvents include: \#3 Contact Cleaner 2000

\#6 Envi-ro-tech 1676 Defluxer

\#7 MSR Universal Solvent \#8a No Ø Tri - aerosol

\#9 Safezone Solvent Flux Remover (MS990/CO2)

\#14 E-Series CFC Free Flux Off 2000

\#15 E-Series Alcohol Blend Flux-Off 2000

Further review of these seven solvents showed that two of the seven could be eliminated because of undesirable qualities. Both Sequence \#7 and \#8a were in a difficult to dispense form, free flow liquid, instead of the more effective/desirable spray form. Furthermore, \#7 MSR Universal Solvent needed to be diluted for industrial use and was very slow to dry after application. Sequence \#8a also posed some difficulty as it left a residue that did not remove easily. Because five adequate solvents without such deficiencies were still available, MSR Universal Solvent and No $\varnothing$ Tri aerosol were eliminated from the list of solvents to be further tested and evaluated. Thus, the remaining five solvents (Seq. \#'s 3,6,9,14, and 15) were then subject to further testing and evaluation by several Fermilab employees who are involved and familiar with circuit board cleaning and the desired results.

\subsubsection{FURTHER INVESTIGATION}

The results from Fermilab personnel who further tested the five remaining solvent candidates were constructive and confirmed the findings of the Preliminary Testing.

The RPTS (Radiation Physics Technical Support) Group gave their results based on different aspects of circuit board cleaning. They assigned the best use for and relative effectiveness to each candidate. According to their findings sequence \#9 Safezone Solvent Flux Remover (MS-990/CO2) by Miller-Stephenson is the best flux remover, \#15 E-Series Alcohol Blend Flux-Off 2000 by Chemtronics is the best residue cleaner, and \#3 Contact Cleaner 2000 by CRC Industries is the best/only choice contact cleaner. They recommend these products.

Accelerator Division personnel agreed that both Chemtronics E-Series Flux-Off 2000 solvents \#14 CFC Free and \#15 Alcohol Blend worked well for flux removal in their 


\begin{tabular}{|c|c|c|}
\hline \multicolumn{3}{|c|}{ 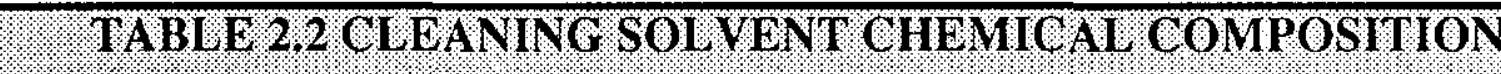 } \\
\hline Seq & Product Name & Chemical Composition \\
\hline 1 & Citra Jinx Organic All Purpose Cleaner & $\begin{array}{l}\text { Citrus Terpenes } \\
\text { Liquified Petroleum Gas }\end{array}$ \\
\hline 2 & Citra Safe Cleaner & $\begin{array}{l}\text { D-Limonene } \\
\text { Carbon Dioxide }\end{array}$ \\
\hline 3 & Contact Cleaner 2000 & $\begin{array}{l}\text { 1,1-Dichloro-1-fluoroethane } \\
\text { Carbon Dioxide }\end{array}$ \\
\hline 4 & CS Cleaner & $\begin{array}{l}\text { D-Limonene } \\
\text { C10-C11 Hydrocarbons } \\
\text { Carbon Dioxide }\end{array}$ \\
\hline 5 & Detergent 8 & $\begin{array}{l}\text { Ethylene Glycol Monobutyl Ether } \\
\text { Dipropylene Glycol Methyl Ether }\end{array}$ \\
\hline 6 & Envi-ro-tech 1676 Defluxer & $\begin{array}{l}\text { Dichlorofluoroethane } \\
\text { Ethyl-S(-)2-hydoxpropionate } \\
\text { Methanol } \\
\text { Chlorodifluoromethane } \\
\text { Carbon Dioxide }\end{array}$ \\
\hline 7 & MSR "Universal Solvent" & $\begin{array}{l}\text { Triethyl Phosphate } \\
\text { Citrus Terpenes } \\
\text { Paraffin Hydrocarbons } \\
\text { 2-Pyrrolidone } \\
\text { Nonylphenoxypoly ethanols } \\
\text { Butyrolactone }\end{array}$ \\
\hline 8 & No $\emptyset$ Tri "Aerosol" (120z) & $\begin{array}{l}\text { Normal Paraffins } \\
\text { 1-chloro-1,1-difluoroethane } \\
\text { Chlorodifluoromethane } \\
\text { Fragrance }\end{array}$ \\
\hline 8 & No $\emptyset$ Tri "Liquid" (20oz) & C11-12 Paraffins \\
\hline 9 & Safezone Solvent Flux Remover (MS-990/C02) & $\begin{array}{l}\text { 1,1-dichloro-1-fluoroethane (96\%) } \\
\text { Methanol (3.9\%) } \\
\text { Nitromethane }(0.1 \%) \\
\text { Carbon Dioxide (3.0\%) } \\
\end{array}$ \\
\hline 10 & MS 260 Cleaner for Plastic, Glass, Metal & $\begin{array}{l}\text { Ethanol } \\
\text { Hydrocarbon Propellant } \\
2 \text { Butoxy Ethanol }\end{array}$ \\
\hline 11 & Arcosolv PTB & $\begin{array}{l}\text { Propylene Glycol T-Butyl Ether } \\
\text { (CAS \# 57018-52-7) }\end{array}$ \\
\hline 12 & Hexyl Acetate, $99 \%$ & $\begin{array}{l}\text { Acetic Acid } \\
\text { Hexyl Ester }\end{array}$ \\
\hline 13 & Isopropyl Alcohol & Isopropyl Alcohol 100\% \\
\hline 14 & E-Series CFC Free Flux-0ff 2000 & $\begin{array}{|ll|}\text { Hydrocarbons (seeMSDS) } & 50.5-71.5 \\
\text { Denatured Alcohol } & 17.11-28.0 \\
\text { Nitroethane } & 0.5-1.5 \\
\text { Isopropanol } & 2.0-4.0 \\
\text { Methylcyclohexane } & 0.1-1.0\end{array}$ \\
\hline 15 & E-Series Alcohol Blend Flux-Off 2000 & $\begin{array}{l}\text { Denatured Alcohol } \\
\text { Isopropyl Alcohol }\end{array}$ \\
\hline
\end{tabular}


operations. The consensus, however, was a preference for the aerosol form of the E-Series CFC

Free Flux-Off 2000 versus the pump spray of the Alcohol Blend for convenience and effectiveness.

In conclusion, based on these two group consensus', the Safezone Solvent Flux Remover (MS-990/CO2) by Miller-Stephenson and the E-Series CFC Free Flux-Off 2000 by Chemtronics are the recommended options we have found for cleaning solvent alternatives to CFC-113 in bench type electronic circuit board cleaning.

A short performance summary on each of the two chosen cleaners is as follows:

>Safezone Solvent Flux Remover is an excellent cleaner which dries very quickly and leaves no residue. Its odor, though apparent, is very slight and ethereal in nature. None of the components in the product are listed as carcinogenic and as far as hazardous reactivity, it is stable. It removes organic rosin fluxes without CFCs or Methyl Chloroform, is excellent for spot flux removal, and is ideally suited for field service, prototype, and production work.

$>$ E-Series CFC Free Flux-Off 2000 has several key performance properties. It removes $R, R M A, R A$, and synthetic flux residues and has low surface tension for quick penetration. It removes oils, greases, ionic and non-ionic soils, is non-corrosive, has high purity, leaves no residue, and evaporates quickly. Caution should be exercised, as this material is flammable.

\subsubsection{FUTURE ALTERNATIVES TO HCFCS}

Hydrochlorofluorocarbons or HCFCs are among the favorable substitutes for CFC-113. This is largely because HCFCs possess many of the same physical properties as CFCs and thus fit in nicely as replacements. For example, when used in machine processes, HCFCs can be directly substituted with few or no alterations to the machine or process. For now, using HCFCs is a viable option, however, HCFCs still have ozone depleting potential (ODP), albeit lower than CFCs, which is accounted for by the shorter atmospheric lifetime of the HCFC molecules. Thus, in the future, like CFCs, HCFCs are targeted for phase-out and will no longer be available as substitutes. This imminent phase-out poses the question whether HCFCs should be used as substitutes now knowing that they will no longer be options in the future. In addition, it is expected that the HCFC phase out schedule will be accelerated. For this reason, the general consensus is to recognize HCFCs as interim measures only rather than solutions to the ODS phase-out issue. 
How does this affect us? As far as this study goes, one of our recommended options, Safezone Solvent Flux Remover (MS-990/CO2), which is a hydrochlorofluorocarbon would be eliminated with the rest of the HCFCs. In order to avoid going through this entire evaluation process again, a comparable non-HCFC option was also found which is the E-Series CFC Free Flux-Off 2000 by Chemtronics. This Chemtronics solvent contains, as titled, no CFCs nor does it contain any HCFCs which gives this product an ODP of 0.00 according to its Environmental Impact Data. Beyond this Chemtronics product, other products, although not considered the "best" options, are also free of HCFCs and should be kept in mind for future use.

Of the products surveyed, those rated as "good" cleaners or better which contain no HCFCs are:

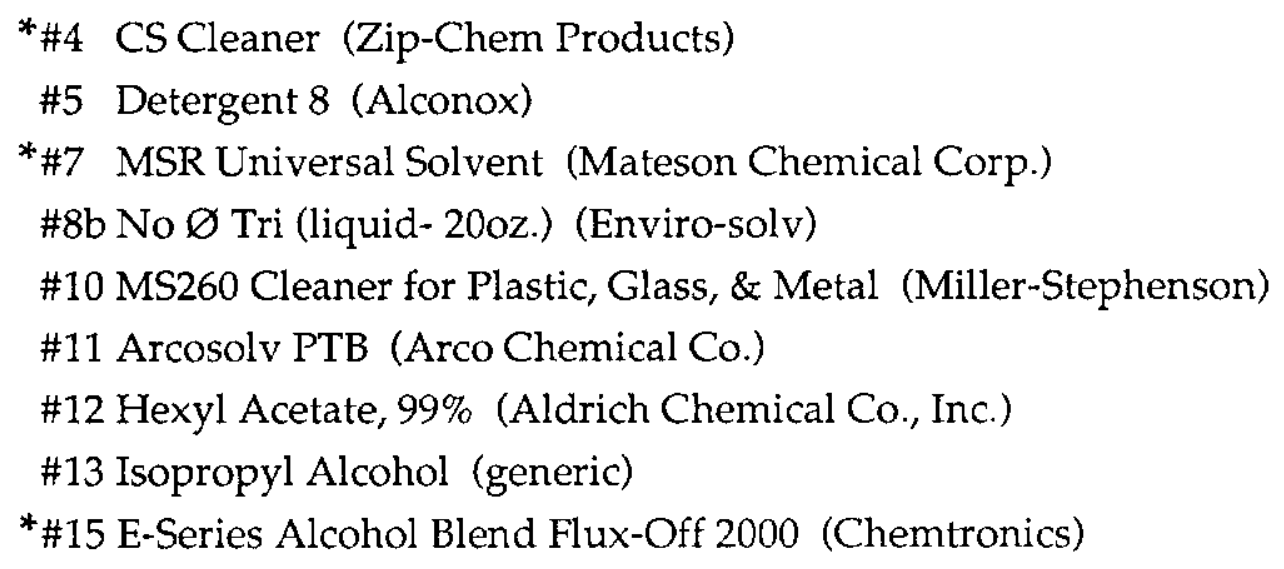

* Indicates the best of these options - limited inconvenience and adequate cleaning potential. Others proved to be messy, slow to dry, or heavily odorous and should be considered only temporary or last options. As mentioned earlier, the slow drying cleaners can be helped with a blow dryer if non-flammable.

In the future, at the time of the HCFC phase out for instance, these options may be consulted if a solvent is required beyond the recommended E-Series CFC Free Flux-Off 2000.

\subsection{NO-CLEAN SOLDERING ALTERNATIVES}

A second process which was included in this investigation was the use of a no-clean soldering process. This represents the ideal solution since cleaning after soldering would no longer be necessary. Elimination of the solvent cleaning operation significantly reduces the emission of ODSs (ozone depleting substances), reduces energy consumption, and reduces product costs. 
The following materials were used in the evaluation of the no-clean solders:

Circuit boards, no-clean solders to be tested (4)

\subsubsection{PROCEDURE}

The evaluation of the no-clean solders lends itself to a less formalized procedure than the cleaning solvent study. In this study, four no-clean solders were evaluated. These four hold the trade names: Cobar Core, Multicore 99C, Multicore Sn96, and Multicore Sn63 (See Appendix B for selected contacts). Several Fermilab employees who are typically involved in the previously mentioned type of soldering operations were asked to use the no-clean solders in the same manner in which they would use the traditional rosin based solder. Based on the performance and content of the no-clean solders tested, the four were ranked as shown in Figure 2.1. Qualities of the solder that were judged or questions that were asked include: How well does the solder bond the material to the board?, Does the solder flow well and easily at accepted soldering iron temperatures?, and Is there any excessive smoke or odor which is irritating?

\subsubsection{RESULTS}

In general, those who tested the no-clean solders were impressed with their performance and were in favor of using such material in operations where appropriate. Furthermore, some no-clean solders contain no or low lead content. This is important as exposure to lead in lead based solders has always been a concern among employees who do a lot of soldering. Based on these findings, no-clean soldering seems to be a viable alternative. See Figure 2.1 for the ranking and specifics on each of the four types of no-clean solders tested. 
FIGURE 2.1

\section{Ranking of Four No-Clean* Solders}

\#1) Cobar Core

- Synthetic flux

- Water soluble

- Leaves no visible residue

- Cleaning unnecessary

- See attached MSDS for contents

\#2) Multicore 99C

- Content: $99.3 \% \mathrm{Sn}, 0.7 \% \mathrm{Cu}$

- Description: X38C

- Leaves slight shiny residue

- Not water soluble

- Residue cleaned with MS-195/CO2 Flux Remover

\#3) Multicore Sn96

- Content: $96 \% \mathrm{Sn}, 4 \% \mathrm{Ag}$

- Description: X38B

- Leaves slight shiny residue

- Not water soluble

- Residue cleaned with MS-195/CO2 Flux Remover

\#4) Multicore $\operatorname{Sn} 63$

- Content: $63 \% \mathrm{Sn}, 0.25 \% \mathrm{Sb}$

- Description: X38B

- Leaves slight clear residue

- Not water soluble

- Residue cleaned with MS-195/CO2 Flux Remover

* No-Clean solder sometimes leaves a residue (as with the three Multicore solders). The "no-clean" title is given as this residue is non-corrosive and thus, for general purposes, is not necessary to clean. With these materials, cleaning is necessary only when used in very sensitive operations or for cosmetic purposes. 


\subsection{OVERVIEW OF REFERENCES}

Much investigation has already been done in regard to replacing ODSs as shown, for example, by the substantial reference list. A good part of this work is accounted for by DOE Facilities such as Battelle, Sandia National Laboratories, Los Alamos National Laboratory, and now Fermi National Accelerator Laboratory. Many of these past studies have been helpful in the development of this investigation. Specifically, though, much of the information surpasses the level of complexity of operations to which this study is focused, namely, bench type electronic circuit board soldering/cleaning. Despite this fact, the ideas presented by other laboratories or groups is key knowledge that can be used to build on what has already been done instead of reinventing the wheel. Here, some key ideas given in selected references are presented in order to produce more insight into the topic at hand.

\subsection{INSIGHTS OF SELECTED REFERENCES INTO CLEANING SOLVENT ALTERNATIVES TQ CFC-113}

The following information is given to broaden the scope of ideas provided in this report. It is the hope that these ideas will provide a better understanding of why CFC-113 solvent replacement is essential for future operations. The heading of each section represents the source from which the information was drawn.

\subsubsection{An Assessment of Alternatives and Technologies for Replacing Ozone-Depleting Substances at DOE Facilities - (Battelle)}

\subsubsection{RECYCLE AND RECOVERY}

A major part in ODS solvent reduction comes from the implementation of an effective recycle/recovery program. According to the UNEP report on Solvents, Coatings, and Adhesives (1991), total solvent emissions can be reduced by $90 \%$ if guidelines on solvent recovery are followed. Using less solvent is also an effective measure which can be accomplished by periodic preventive maintenance, engineering controls, operator equipment training, and spill prevention techniques. (p. 28)* Also, included from this report is a figure titled "Alternatives For ODS Solvents CFC-113 and Methyl Chloroform" (p. 31) which lists alternative cleaning solvent options such as aqueous, semi-aqueous, alcohols and ketones, and HCFCs. No-clean options include low-solid fluxes and inert gas wave soldering.

\footnotetext{
* Throughout section 3.0, the page numbers in parentheses indicate the page number within the report which tilles the section in italics.
} 


\subsubsection{THE ROLE OF MIL-SPECS AND MIL-STANDARDS}

It is an interesting note that only fairly recently (in 1991) did solvent alternatives to CFC-113 become a viable option. Up until then, military specifications (Mil-specs) and military standards (Mil-standards) resisted the phase-out of CFC-113. In 1991, though DOD modified Mil-standard 2000 to allow and recommend that CFC based solvents be phased out. This change in DOD solvent requirements make the pursuit of CFC-113 alternatives much easier for both DOE Facilities and general industry who traditionally comply with such standards. (p. 28)

\subsubsection{Evaluation of a No-Clean Soldering Process Designed to Eliminate the Use of Ozone Depleting Chemicals - (CRADA)}

A January 1991 issue of Electronics indicates that no less than 20\% of ODS emissions is caused by cleaning processes of electronic circuit boards and other electronic gear. (p. 1)

Furthermore, a November 1992 study by CRADA (Cooperative Research and Development Agreement) addresses the no-clean soldering process in a report entitled Evaluation of a No-Clean Soldering Process Designed to Eliminate the Use of Ozone Depleting Chemicals. The purpose of this program was to "determine if the no-clean process produces hardware that is as reliable as that soldered with the existing rosin-based flux solvent cleaning process" (R.L. Iman, 1). The results showed that the no-clean process, as far as ionic cleanliness is concerned, was equivalent and in some cases better than the traditional rosin flux process used to date. Visual solder quality equivalent to the rosin flux solvent process was also achieved. These results were duplicated in the Fermilab study of no-clean solders used for purposes applicable for Fermilab operations, namely bench type electrical circuit board soldering repair and modification operations. Although on a much smaller scale, these bench type operations require the same attention to ionic cleanliness and solder quality.

The no-clean soldering processes investigated in the CRADA report were more than manual repair/modification operations on circuit boards. In this case, a SEHO wave soldering machine at Motorola GEG was used to perform all soldering operations (See Figure 2.2). Operations such as this or other operations which would require the purchase of additional equipment is beyond the scope of the Fermilab study. The results, however, are interesting and can be used to predict the possible reactions of the no-clean soldering process in the soldering operations. For example, some other results found by the CRADA study which 
could not be duplicated in this study because of time, equipment, or resource constraints are that the no-clean soldering process is capable of producing electrically and mechanically reliable hardware over a wide range of processing parameters and did not degrade product shelf life. In addition, the indirect benefits that would be expected from this process would be a positive impact on the depletion of the ozone layer and significant reduction of time involved in soldering operations. It is the hope that the use of no-clean solders, in cases where it is deemed appropriate, can bare some of these same benefits as were found in the CRADA study.

\subsubsection{Waste Minimization Program Accomplishments Fiscal Years 1990, 91, and 92}

In an excerpt labeled Alternative Cleaning Methods Minimize Hazardous Chemicals (Stiefeld, SOLV-05), d-limonene is recommended as a base line alternative to trichloroethylene and chlorinated fluorocarbons in many production processes. We recognized this in our study in sequence \#2 Citra Safe Cleaner and \#4 CS Cleaner which both contained d-limonene (see Table 2.2) and were evaluated to be good cleaners (see Table 2.1). The CS Cleaner by Zip-Chem Products was also listed in section 2.1.4 as one of the best non-HCFC options as far as cleaning potential and relative convenience is concerned. (p. 21)

\subsubsection{Eliminating CFC-113 and Methyl Chloroform in Precision Cleaning Operations}

Exibit 3 in the above titled report highlights the phase-out/reduction schedule for CFC113 since 1986 under the U.S. Clean Air Act and the Montreal Protocol. (p. 4) Note that although some of the dates have since changed, this schedule is an indication of the early efforts which have been made in the reduction of ODSs. An accelerated schedule for the phase-out of the most damaging ODSs was mandated in February 1992 by President George Bush.

\subsubsection{Solvent Substitution}

One incentive set by Congress to discourage the use of ODSs in 1990 is a tax on CFC-113 and 1,1,1-trichloroethane (TCA). The tax on CFC-113 was $\$ 1.10$ per pound in January 1990 and on TCA was $\$ 0.137$ per pound in January 1991. With inflation, these costs have increased and will continue to do so up until the targeted phase-out dates for CFC-113 and TCA as set by the Clean Air Act. (p. 127) 


\subsection{INSIGHTS OF SELECTED REFERENCES INTO THE NO-CLEAN SOLDER ALTERNATIVE}

The following information is given to broaden the scope of ideas provided in this report concerning the no-clean soldering option. Again, the heading of each section represents the source from which the information was drawn.

\subsubsection{Evaluation of a No-Clean Soldering Process Designed to Eliminate the Use of Ozone Depleting Chemicals - (CRADA)}

Some interesting projections of waste and energy savings using the no-clean versus rosin/flux solvent cleaning soldering in the year 2010 for DOE:

- Waste savings: 18,000 tons of CFC-113

- Energy savings: $1.4 \mathrm{E} 13 \mathrm{BTUs}$

- Operation Cost: $\$ 100,000$ - $\$ 200,000$ yearly with rosin/flux cleaning soldering (present)

$v s$.

$\$ 25,000$ one time cost for no-clean process (p. 116)

\subsubsection{Solvent Substitution}

As of December 1990, it was reported that nearly half of the electronics companies in the U.S. use water soluble fluxes. These fluxes generally have a higher activity than rosin fluxes which produces a better soldering performance. Despite the benefits, some difficulties have evolved, for example: the water soluble flux is potentially corrosive to the circuit board assemblies, it can produce high impedant circuitry, and it can occasionally form insoluble residues or leach lead from the circuit boards. (p.132)

Such difficulties with water soluble fluxes have prompted some to turn to the use of low solids "no-clean" fluxes which eliminate cleaning equipment and are friendlier to the environment. It is also noted that DOD has not viewed the use of water soluble or low solid "no-clean" fluxes favorable. Finally, another set of alternatives to reduce/eliminate solvent use in cleaning electronic hardware are processes such as fluxless soldering, inert atmospheric soldering, and organic solders (conductive adhesives). (p.133) 


\section{Protection For the 90's}

All the no-clean fluxes leave some residue. In many cases, though, it is not visually apparent. Also, the difference between no-clean and regular fluxes is mildness. The no-clean fluxes are less reactive. Generally, they consist of alcohol and a mixture of organic acids. Furthermore, there is lower emission of VOCs because less flux is used and lower numbers of chemicals are used in the process. 


\subsection{CONCLUSIONS}

With the knowledge that CFCs and other ODSs will be phased out in a timely manner as mandated by the Clean Air Act, Fermilab has made cooperation with these guidelines a priority. Through this study and other research, alternatives to CFC-113 have become more accessible and will soon be widely available throughout Fermilab via the stockroom supply.

This study provides two general alternatives to the use of CFC-113 in bench type circuit board cleaning: non-CFC cleaning solvents and no-clean solders. At this time, the most practical and accepted alternative is the use of non-CFC cleaning solvents. This is preferred primarily because no-clean soldering is still under observation at Fermilab and requires further investigation. Furthermore, no-clean soldering would be difficult to institute site-wide in an expeditious manner.

The preferred solvents, namely Safezone Solvent Flux Remover and E-Series CFC Free FluxOff 2000, were found to be the best alternatives for the purpose of bench type electronic circuit board cleaning at Fermilab. Surely many solvents listed in section 2.1.3.1 can be of use to the electronics community; however, for this specific purpose the two recommendations were made to narrow the choices for stockroom quality purposes.

With the help and cooperation of the Fermilab community and manufacturers of nonCFC solvents, Fermilab will be right on schedule with Title VI of the Clean Air Act now and ready in anticipation of the pending HCFC phase-out in the future. 


\section{REFERENCES}

1. R.L. Iman and D.J. Anderson (Sandia National Laboratories). "Evaluation of a No-Clean Soldering Process That Eliminates the Use of Ozone Depleting Chemicals," Pollution Prevention Advisor. Winter 1993, vol. 3 no. 1 p.p. 5-6.

2. ICLOP Technical Committee. Eliminating CFC-113 and Methyl Chloroform in Precision Cleaning Operations. June 1991, U.S. Environmental Protection Agency Stephen O. Anderson.

3. ICOLP Technical Committee. Conservation and Recycling Practices for CFC-113 and Methyl Chloroform. June 1991, U.S. Environmental Protection Agency - Stephen O. Anderson.

4. ICLOP Technical Committee. Alternatives for CFC-113 and Methyl Chloroform in Metal Cleaning. June 1991, U.S. Environmental Protection Agency - Stephen O. Anderson.

5. C.W. Purcell, K.B. Miller, J.R. Friedman, R.D. Rapoport, D.R. Conover, P.L.Hendrickson, and T.C. Koss. An Assessment of Alternatives and Technologies for Replacing OzoneDepleting Substances at DOE Facilities. October 1992: Prepared for the U.S. Department of Energy, Office of Environmental Guidance under contract no. DE-AC0676RLO 1830 - Battelle

6. ICOLP Technical Committee. Aqueous and Semi-Aqueous Alternatives for CFC-113 and Methyl Chloroform Cleaning of Printed Circuit Board Assemblies. June 1991, U.S. Environmental Protection Agency - Stephen O. Anderson.

7. Conference Proceedings Compilation of: The 1992 International CFC and Halon Alternatives Conference - Stratospheric Ozone Protection For the 90's. September 29 - October 1, 1992. Washington Hilton, Washington, D.C.

8. A Proceedings/Compendium of Papers: Solvent Substitution. Based on the First Annual International Workshop on Solvent Substitution on December 4-7, 1990 in Phoenix, Arizona. Prepared by the Weapons Complex Monitor Forums under DOE contract no. DE-AC07-76ID01570.

9. R.L. Iman, D.J. Anderson, M.E. Armendariz, L. Lichtenberg, P. Van Buren, M.T. Paffett. Evaluation of a No-Clean Soldering Process Designed to Eliminate the Use of Ozone Depleting Chemicals. November 1992, CRADA (Cooperative Research and Development Agency).

10. Department of Energy Defense Programs Integrated Contractors. Waste Minimization Program Accomplishments Fiscal Years 1990.91, \& 22. 1992, Los Alamos National Laboratory.

11. U. S. EPA. Vendor List - Alternatives For CRC-113 and Methyl Chloroform in Electronics Cleaning. March 25, 1993, Significant New Alternatives Policy (SNAP) Program Stratospheric Protection Division U. S. EPA. 


\section{APPENDIX A}

\section{CATALOG OF DATA FOR CLEANING SOLVENTS TESTED}

(NOTE: For more information on cleaning solvents, contact the product manufacturer - See Appendix B for contact addresses and phone numbers) 
Sequence Number 1

Product Name Citra Jinx Organic All Purpose Cleaner

Manufacturer Claire Manufacturing Company

ACGIH TLV OSHA PEL

Chemical Composition Citrus Terpenes

$\mathrm{N} / \mathrm{A}$

N/A

Liquified Petroleum Gas

$1000 \mathrm{ppm} \quad 1000 \mathrm{ppm}$

Physical State Spray; appreciably soluble in water

Physical Appearance Opaque, whitish liquid (foam)

odor Citrus odor

Hazardous Properties Inhalation may cause dizziness, drowsiness, and throat irritation. Eye contact may cause irritation.

Skin contact may cause slight redness.

Flammable Limits: LEL- 1.8 UEL-9.2 (non-flammable)

Carcinogenic: no

PPE required Chemical resistant gloves

Chemical safety glasses are recommended

Impervious clothing

Handling Storage Do not store above $54 \mathrm{C}-130 \mathrm{~F}$. Dropping of container may cause bursting. Keep away from heat and flame. Use adequate ventilation.

Unusual Hazards NONE

Comments Contact: James Valadez (Manufacturers rep) Ph: (708) 530-0007

Other ingredients not listed in Chem Comp: NONE

Type of output: white foam 
APPENDIX A CATALOG OF DATA FOR CLEANING SOLVENTS TESTED

Sequence Number 2

Product Name Citra Safe Cleaner

Manufacturer Zip-Chem Products

Chemical Composition D-Limonene Carbon Dioxide

ACGIH TLV OSHA.PEL

N/A N/A

$5000 \mathrm{ppm} \quad 5000 \mathrm{ppm}$

Physical State Spray; Insoluble in water.

Physical Appearance Yellow to amber liquid

odor Citrus odor

Hazardous Properties May cause temporary discomfort to eyes.

Frequent exposure may induce dermatitis in sensitive individuals.

Flammable Limits: LEL - 0.7\% UEL - $6.1 \%$

Carcinogenic: no

PPE required Butyl lined gloves

Chemical goggles; If working in area with extremely high vapor concentration, use self contained breathing apparatus.

Handling Storage Do not store above $120 \mathrm{~F}$, near heat, sparks, or flames.

Use only in well ventilated area (ventilation by local or mechanical device).

Unusual Hazards Dense black smoke produced upon ignition (carbon oxides).

Comments Ph: (408) 729-0291

Other ingredients not listed in Chem Comp: NONE

Type of output: clear liquid spray 


\section{Sequence Number 3}

Product_Name Contact Cleaner 2000

Manufacturer CRC Industries

Chemical composition 1,1-Dichloro-1-fluoroethane

ACGIH TLV OSHA PEL Carbon Dioxide

N/A N/A

5000ppm $5000 \mathrm{ppm}$

Physical State Spray; slightly soluble in water

Physical Appearance Clear colorless liquid

Qdor Ether odor

Hazardous Properties Inhalation can cause dizziness, lightheadedness; High levels may cause asphyxiation or cardiac arrhythmias.

May cause defatting or irritation to skin; May cause eye irritation.

Flammable Limits: LEL - 7.6 UEL - 17.7 (no flash point)

Carcinogenic: no

PPE required Vapor concentration above TLV - use self-contained breathing apparat.

Solvent resistent gloves

Safety glasses

Handling Storage Store in cool, dry area.

Unusual Hazards Aerosols may explode when heated above 120F

Comments Contact: John Shortness Ph: (708) 655-0298

--Cleaner leaves no residue

Other ingredients not listed in Chem Comp: NONE

Type of output: clear liquid spray 
Sequence Number 4

Product Name CS Cleaner

Manufacturer Zip-Chem

ACGIH TLV OSHA PEL

N/A N/A

Chemical Composition D-Limonene
C10-C11 Hydrocarbons

not establ. not establ.

Carbon Dioxide

$5000 \mathrm{ppm} 5000 \mathrm{ppm}$

Physical State Spray; not soluble in water

Physical Appearance clear

oder Mild citrus odor

Hazardous Properties Accute: May cause eye irritation; low order acute oral and dermal toxicity. Chronic: Prolonged use may lead to mild irritation, defatting, and dermatitis (skin).

Flammable Limits (in air by vol): LEL - 0.7\% UEL - $7.0 \%$

Carcinogenic: no

PPE required Chemical resistant gloves

Splash goggles or face shield

Handling Storage Keep away from heat and open flame

Unusual Hazards NONE

Comments Ph: (408) 729-0291

: (800) 648-2661

Other ingredients not listed in Chem Comp: NONE

Type of output: clear liquid spray 
Sequence Number 5

Product Name Detergent 8

Manufacturer Alconox

Chemical Composition Ethylene Glycol Monobutyl Ether Dipropylene Glycol Methyl Ether
ACGIH TLV QSHA PEL

25 ppm $\quad 50$ ppm

$100 \mathrm{ppm} \quad 100 \mathrm{ppm}$

Physical_State Spray; complete solubility in water

Physical_Appearance Clear liquid

odor Slight ammonia odor

Hazardous Properties Inhalation of vapors or skin contact may prove locally irritating.

Ingestion may cause discomfort and/or nausea.

Inhalation may cause drowsiness in poorly ventilated areas.

Flammable Limits: no data available

PPE required Protective gloves - required

Eye protection - recommended

Eye wash station should be available.

Handling Storage Open container slowly to reduce pressure build-up

\section{Unusual Hazards NONE}

Comments Ph: (212) 473-1300

Other ingredients not listed in Chem Comp: NONE

Type of output: Liquid requires dilution with water $(6 \mathrm{oz} / \mathrm{gal}$ water). 
Sequence Number 6

Product_Name Envi-ro-tech 1676 Defluxer

Manufacturer Tech Spray

Chemical composition

Dichlorofluoroethane

Ethyl-S(-)2-hydoxpropionate (TLV set by

Methanol

Chlorodifluoromethane

Carbon Dioxide
ACGIH TLV OSHA PEL

N/A N/A

$335 \mathrm{ppm} \quad \mathrm{N} / \mathrm{A}$

Allied Signal Inc)

$200 \mathrm{ppm} \quad 200 \mathrm{ppm}$

$1000 \mathrm{ppm}$

$5000 \mathrm{ppm} \quad 5000 \mathrm{ppm}$

Physical State Spray; <5 solubility in water

Physical_Appearance Clear water-white mobile liquid

odor Slight ether odor

Hazardous Properties Breathing high concentrations of vapor may cause light headedness, giddiness, shortness of breath, confusion, and may lead to narcosis, cardiac irregularities, unconsciousness, or could even become fatal. Liquid contact will irritate eyes or cause conjunctivitis. Prolonged use could cause defatting of the skin. Material is non-flammable.

PPE required Solvent resistant gloves such as Neoprene or PVA; Splashproof safety goggles or glasses. If levels exceed TLV, increased ventilation or organic vapor mask required.

Handling Storage None specified.

Unusual Hazards

Aerosol cans may erupt with force at temperatures above $120 \mathrm{~F}$

Comments Ph: (806) 372-8523

(800) $858-4043$

Other ingredients not listed in Chem Comp: NONE

Type of output: clear liquid spray 
Sequence Number 7

Product Name MSR "Universal Solvent"

Manufacturer Mateson Chemical Corp.

Chemical Composition Triethyl Phosphate

Citrus Terpenes

Paraffin Hydrocarbons

2-Pyrrolidone

Nonylphenoxypoly ethanols

Butyrolactone

\begin{tabular}{cc} 
ACGIH TLV & OSHA PEL \\
${ } }$ & N/A \\
\hdashline-- & N/A \\
$100 \mathrm{ppm}$ & N/A \\
$\cdots \cdots$ & N/A \\
$-\cdots$ & N/A \\
$\cdots$ & N/A
\end{tabular}

Physical State Liquid; dispersible only in water

Physical Appearance Clear, colorless, light amber

odor Aromatic odor

Hazardous Properties May cause anesthetic effects or eye irritation. Flammable Limits: LEL - $1.4 \%$ UEL - $6.9 \%$

PPE required If sprayed or misted, use an appropriate NIOSH approved respirator for organic vapor. Use rubber gloves and safety glasses. Eye wash station should be available during use.

Handling Storage Do not store in plastic containers to dispense.

Unusual Hazards Low fire hazard when exposed to heat and flames.

comments ----> This solvent is to be diluted for industrial use.

Ph: (215) 423-3200

Other ingredients not listed in Chem Comp:

- Aromatic Petroleum Solvents

- Penetrants and Wetting Agents

- Inert Ingredients $(3.23 \%)$

Type of output: Liquid solvent requires dilution. 
Sequence Number 8a

Product Name No 0 Tri "Aerosol" (12oz)

Manufacturer Enviro-solv

Chemical Composition Normal Paraffins

1-chloro-1,1-difluoroethane

ACGIH TLV OSHA PEL

Chlorodifluoromethane

$\mathrm{N} / \mathrm{A}$

$N / A$

$\mathrm{N} / \mathrm{A} \quad \mathrm{N} / \mathrm{A}$

Fragrance

$1000 \mathrm{ppm} \quad 1000 \mathrm{ppm}$

$\mathrm{N} / \mathrm{A} \quad \mathrm{N} / \mathrm{A}$

Physical_state Spray; Solubility in water is negligible.

Physical Appearance Colorless

odor Mild citrus odor

Hazardous Properties May cause eye irritation, skin defatting or dryness. Excessive inhalation may cause central nervous system depression, anesthetic effects, and increased cardial irritability.

Flammable Limits: LEL - 1 UEL - 7

Carcinogenic: no

PPE required Local exhaust hood or fan

Protective gloves

Safety glasses

Handling Storage Maximum storage temperature - 120F

Unusual Hazards At elevated temperatures (over 120F) containers may vent, rupture or burst.

Comments Contact: James Rogers Ph: (708) 223-5914

Pricing per unit ( 1 unit $=12$ cans)

Purchasing: <or $=5$ units $-->\$ 86.00 /$ unit

10 units $-->\$ 78.00 /$ unit

20 units $\rightarrow \$ 71.00 /$ unit

Other ingredients not listed in Chem Comp: NONE

Type of output: clear, fine spray 
Sequence Number $8 b$

Product Name No 0 Tri "Liquid" (200z)

Manufacturer Enviro-solv

Chemical Composition C11-12 Paraffins

ACGIH TLV OSHA PEL

$\mathrm{N} / \mathrm{A}$

N/A

Physical State Liquid; Solubility negligible in water

Physical Appearance Clear, colorless liquid

odor Pleasantly scented

Hazardous Properties May cause eye irritation, skin defatting, or dryness. Injestion may irritate gastrointestinal tract. Aspiration into lungs may cause injury. Flammable Limits: LEL - 1 UEL -6

Carcinogenic: no

PPE required Hood or fan for local exhaust

Rubber or plastic gloves

safety glasses

Handling Storage Store in a cool, dry area.

Read entire label before use.

Unusual_Hazards NONE

Comments Contact: James Rogers Ph: (708) 223-5914

Pricing per unit ( 1 unit $=12$ cans):

Purchasing: <or $=5$ units $-->>\$ 82.00 /$ unit

10 units $--\rightarrow \$ 74.00 /$ unit

20 units --->\$67.00/unit

Other ingredients not listed in Chem Comp:

- Fragrance

Type of output: liquid solvent 
APPENDIX A CATALOG OF DATA FOR CLEANING SOLVENTS TESTED

\section{Sequence Number 9}

Product Name Safezone Solvent Flux Remover (MS-990/C02)

Manufacturer miller-stephenson

Chemical Composition 1,1-dichloro-1-fluoroethane (96\%)

Methanol (3.9\%)

Nitromethane $(0.1 \%)$

Carbon Dioxide (3.0\%)

$\begin{array}{cc}\text { ACGIH TLV } & \text { OSHA PEL } \\ \text { not establ. } & \text { not establ. } \\ 200 \mathrm{ppm} & 200 \mathrm{ppm} \\ 100 \mathrm{ppm} & 100 \mathrm{ppm} \\ 5000 \mathrm{ppm} & 5000 \mathrm{ppm}\end{array}$

Physical State Spray; Slight solubility in water

Physical_Appearance Clear, colorless

odor Ether odor

Hazardous Properties At low concentration, may cause headache, dizziness, nausea, loss of concentration, and irritation. High exposure levels may cause intoxication, cardiac arrhythmia.

May cause defatting of the skin. Eye irritation may cause conjunctivitis. Flammable Limits: LEL - 7.5 UEL - 19.2

PPE required Use in well ventilated area.

Neoprene gloves

Splash goggles

Handling Storage Do not store near sources of heat, indirect sunlight, or where temperatures exceed $120 \mathrm{~F} / 49 \mathrm{C}$.

Rotate stock to shelf life of 1 year.

Unusual Hazards NONE

comments Ph: (708) 966-8468

(800) $992-2424$

Pricing: 12-143 cans 144-575 cans

$\$ 7.95 \quad \$ 7.75$

Other ingredients not listed in Chem Comp: NONE

Type of output: clear, fine spray 
APPENDIX A CATALOG OF DATA FOR CLEANING SOLVENTS TESTED

Sequence Number 10

Product Name MS 260 Cleaner for Plastic, Glass, Metal

Manufacturer miller-stephenson

ACGIH TLV OSHA PEL

Chemical Composition Ethanol

Hydrocarbon Propellant

2 Butoxy Ethanol

$1000 \mathrm{ppm} \quad 1000 \mathrm{ppm}$

$1000 \mathrm{ppm} \quad 1000 \mathrm{ppm}$

$25 \mathrm{ppm} \quad 50 \mathrm{ppm}$

Physical State Spray, Miscible in water

Physical Appearance Wide, hollow cone spray, semi stable form

odor Floral fragrance

Hazardous Properties Excessive ingalation of concentrated vapor can cause dizziness, narcosis, suffocation or may irritate nasal passages. Skin contact may causes redness or irritation. Eye contact may cause irritation and oral intake may cause irritation to digestive tract.

Non-flammable. Carcinogenic: no

PPE required Use adequate ventilation.

Neoprene or rubber gloves and chemical splash goggles should be available.

Handling Storage Pressurized aerosol containers at elevated temperatures may vent, rupture or burst and add to flying and falling debris. Store at temperatures below $38 \mathrm{C}$.

Unusual Hazards Foam may burn slightly due to escaping propellant gases but combustion is not sustained.

Comments Ph: (708) 966-8468

(800) $992-2424$

Other ingredients not listed in Chem Comp:

- Butane

- Isobutane

Type of output: White foam 
Sequence Number 11

Product Name Arcosolv PTB

Manufacturer Arco Chemical Company

Chemical Composition Propylene Glycol T-Butyl Ether CAS \# 57018-52-7

ACGIH TLV OSHA.PEL not listed not listed

Physical State Liquid; appreciably soluble in water

Physical Appearance Clear colorless liquid

oder Ether odor

Hazardous Properties Moderately combustible liquid; Severe eye irritant; Slight inhalation hazard; Slight skin absorption hazard; Slight skin irritant; Slight ingestion hazard.

Carcinogenic: no

Released vapors can burn in open or explode if confined.

PPE required NIOSH/MSHA approved respiratory protection equiptment is recommended. Eye protection, both chemical goggles and face shield, must be worn to protect from splash. Protective gloves should be worn.

Handling Storage Store only in tightly closed, properly vented containers away from heat, sparks, open flame, or strong oxidizing agents. Flammable/combustible residue remains after emptying. Some plastics and rubbers are attacked by glycol or ether esters.

Unusual Hazards Local exhaust or general room ventilation is usually required.

comments -.--> This solvent is for industrial use only.

Phone: (800) 321-7000 (customer service - INFO)

(800) 424-9300 (emergency - chemt)

(215) 353-8300 (emergency - Arco)

Pricing:

Other ingredients not listed in Chem Comp: NONE listed

Type of output: clear colorless liquid 
Sequence Number 12

Product Name Hexyl Acetate, 99\%

Manufacturer aldrich chemical co., inc.

Chemical Composition

Acetic Acid

ACGIH TLY OSHA PEL

Hexyl Ester

$10 \mathrm{ppm} \quad 10 \mathrm{ppm}$

Physical State Liquid

Physical Appearance Colorless liquid

Odor Banana Oil / sweet smelling

Hazardous Properties May be harmful by inhalation, ingestion, or skin absorption.

May cause irritation.

Flammable: keep away from sources of ignition. No Smoking.

PPE required Wear appropriate NIOSH/MSHA - approved respirator, chemical resistant gloves, safety goggles, and other protective clothing.

Handling_Storage Mechanical exhaust required. Safety shower and eye bath available. Wash thoroughly after handling. Keep tightly closed. Keep away from heat, sparks, and open flame. Store in a cool, dry place.

Unusual Hazards Fire Hazards: Vapor may travel considerable distance to source of ignition and flashback. Container explosion may occur under fire conditions. Forms explosive mixtures in air.

Comments Ph: (414) 273-3850

Other ingredients not listed in Chem Comp: NONE

Type of output: in liquid form 
Sequence Number 13

Broduct Name Isopropyl Alcohol

Manufacturer Generic

Chemical Composition Isopropyl Alcohol 100\%

ACGIH TLV OSHA PEL

400 ppm 400 ppm

Physical state Liquid, free flowing in small bottle

Physical Appearance Clear, colorless liquid

odor Slight non-residual alcohol odor (threshold odor concentr. $=28.2 \mathrm{ppm}$ )

Hazardous Properties Class 1B flammable liquid.

May cause mild irritation of the eyes, nose, throat at TLV; above TLV may cause headache, nausea, mild narcosis.

Will irritate the eye on contact and if ingested will cause various internal complications (see MSDS).

BPE required Provide general and local exhaust ventilation (explosion proof) to meet TLV. Impervious gloves and safety glasses during normal use are required.

Handling Storage Do Not store in aluminum containers.

Store in closed container at room temperature.

Absorb small spills with paper towel.

See MSDS for further spill, leak, and disposal procedures.

Unusual Hazards Ground and bond containers and equipment when transfering or pouring liquid. Use non-sparking tools.

Comments Other ingredients not listed in Chem Comp: NONE 
APPENDIX A CATALOG OF DATA FOR CLEANING SOLVENTS TESTED

Sequence Number 14

Product_Name E-Series CFC Free Flux-Off 2000

Manufacturer Chemtronics

Chemical Composition Hydrocarbons (see MSDS)

Denatured Alcohol

Nitroethane

Isopropanol

Methylcyclohexane

$\begin{array}{cc}\text { ACGIH TLV } & \text { OSHA PEL } \\ \text { see MSDS } & \text { see MSDS } \\ \text { see MSDS } & \text { see MSDS } \\ 100 \mathrm{ppm} & 100 \mathrm{ppm} \\ 400 \mathrm{ppm} & 400 \mathrm{ppm} \\ 400 \mathrm{ppm} & 400 \mathrm{ppm}\end{array}$

Bhysical State Aerosol spray

Physical_Appearance Clear, colorless liquid

odor Mild hydrocarbon odor

Hazardous Properties Product is flammable: LEL/UEL: not established

Liquid will irritate eyes and skin under repeated or prolonged exposure Breathing high concentrations of product may produce drowsiness and a headache.

PPE required Wear a positive pressure, air-supplied respirator in situations where potential for airborne exposure. Wear safety glasses with side shields and chemically resistant gloves when handling this material.

Handling Storage Use with adequate ventilation. Store in a cool, dry place, away from heat, sparks, or flames. Keep container tightly closed when not in use. Do not store in direct sunlight.

\section{Unusual Hazards NONE}

comments Contact: Chemtronics Inc.

Phone: $800 / 645-5244$

Type of output: Aerosol spray

Other ingredients not listed in Chem Comp:

Hydrocarbons: n-hexane, 2-Methylpentane, 3-Methylpentane, 2,3-Dimethylbutane, 2,2-Dimethylbutane

Denatured Alcohol a mixture of: ethanol, methanol, methyl isobutyl ketone, ethyl acetate

Carbon dioxide (See MSDS for complete list and TWAs/PELs) 
APPENDIX A CATALOG OF DATA FOR CLEANING SOLVENTS TESTED

Sequence Number 15

Product Name E-Series Alcohol Blend Flux-Off 2000

Manufacturer Chemtronics

Chemical Composition Denatured Alcohol

ACGIH TLV OSHA PEL

Isopropyl Alcohol

$1,000 \mathrm{ppm} \quad 1,000 \mathrm{ppm}$

$400 \mathrm{ppm} \quad 400 \mathrm{ppm}$

\author{
Physical State Aerosol spray \\ Physical_Appearance Clear, colorless liquid \\ odor Alcohol odor \\ Hazardous Properties Carcinogenic: No \\ Inhalation of high concentration may cause irritation; Ingestion may \\ result in irritation of the lining of the GI tract; Contact with skin may \\ cause dermal irritation. \\ Flammable Limits: LEL - 2\%, UEL - $12 \%$ (by air volume) \\ PPE required Protective gloves: rubber \\ Eye protection: Safety glasses, goggles, shields \\ Other: Eye bath and protective clothing; good ventilation required \\ Handling Storage Do not store near sources of heat, in direct sunlight, or where \\ temperatures exceed 120F. Do not store near acids or other oxidizing \\ materials. Wash hands after handling and before eating. Rotate stock.
}

Unusual Hazards Medical conditions possible aggravated by exposure: Persons with pre-existing conditions of the skin and respiratory system may be more susceptible to the toxic effects of this product.

comments Contact: Chemtronics Inc.

Phone: $800 / 645-5244$

Type of output: Aerosol spray 
APPENDIX B

SELECTED CONTACTS 


\section{ALTERNATIVE SOLVENTS}

Claire Manufacturing Co.

Attn: James Valadez

500 Vista Ave.

Addison, IL 60101

708/543-7600

\section{Zip Chem Products}

1860 Dobbin Dr.

San Jose, CA 95133

Emergency: 800/424-9300

Information: 408/729-0291

$800 / 648-2661$

FAX: 408/272-8062

CRC Industries, Inc.

885 Louis Drive

Warminster, PA 18974

215/674-4300

Local contact:

John Shortness

708/655-0298

Alconox Inc.

215 Park Avenue South

New York, NY 10003

Emergency: 212/473-1300

Information: 212/473-1300

Tech Spray

Technical Services Dept.

P.O. Box 949

Amarillo, TX 79105-0949

Phone: 806/372-8523

Toll Free: $800 / 858-4043$

FAX: $806 / 372-8750$

Mateson Chemical Corp. 1025 E. Montgomery Ave. Philadelphia, PA 19125

Phone: 215/423-3200
Enviro-Solv

Attn: James Rogers

P.O. Box 783

Grayslake, IL 60030-0783

Phone: 708/223-5914

Emergency: 800/752-7869

Miller-Stephenson Chemical Co.

Attn: Judith Quinby

George Washington Highway

Danbury, CN 06810

Emergency: 203/797-2212

$800 / 424-9300$

Chicago Office:

6348 Oakton Street

Morton Grove, IL 60053

Phone: 708/966-2202

\section{Arco Chemical Company \\ 3801 West Chester Pike \\ Newtown Square PA 19073 \\ Emergency: 800/424-9300 \\ 215/353-8300 \\ Information: $800 / 321-7000$}

Aldrich Chemical Co., Inc.

P.O. Box 355

Milwaukee, WI 53201

Contact: $414 / 273-3850$

FAX: 414/273-4979

\section{Chemtronics}

8125 Cobb Center Dr.

Kennesaw, GA 30144

Product Info: 800/TECH-401

Customer Service: 800/645-5244

Emergency (Chemtec): 800/424-9300

FAX: $404 / 424-4267$

Local contact:

Ray Lulewicz

5928 lyman Ave.

Downers Grove, II. 60516 


\section{NO-CLEAN SOLDERS}

\section{Cobar}

7557 Rambler Road

Suite 750

Dallas, TX 75231

Phone: 214/361-6454

Telefax: 214/407-0954

Local contact:

Maurice "Moe" Harland

Ecco Venture Systems, LTD.

644 Oak Street

West Chicago, IL 60185

Off: $708 / 293-4499$

FAX: 708/293-4822

\section{Multicore}

1751 Jay Ell Drive

Richardson, TX 75081

Phone: 214/238-1224

FAX: $214 / 473-0288$ 


\section{APPENDIX C}

TASK DESCRIPTION DOCUMENT 


\section{TASK DESCRIPTION DOCUMENT \\ TDD NO $4100(-10)$}

\section{FREON 113 SUBSTITUTES}

\section{Scope Narrative}

Freon 113 is a chlorofluorocarbon (CFC) which is widely used in the DOE as a solvent for cleaning metal parts. It is a good solvent for oils, grease and specifically rosin soldering flux. Its sweet smell evaporates quickly, it is not flammable, and it leaves negligible residue. It does, however, have a high ozone depleting potential ( 0.8 vs. CFC-12 being 1.0). Production of Freon 113 will soon be curtailed and then eliminated. It is presently heavily taxed, has become expensive, and is expected to continue to increase in price.

During usage, in many applications, it is wiped on or sprayed on parts. This leads to waste as fugitive emissions. This can be somewhat overcome by using recovery equipment which, however, is not $100 \%$ efficient. Solvent in these systems gets dirty and must be recovered or disposed of. In order to minimize waste production it is incumbent upon us to find a substitute for Freon 113 . We will explore some substitutes for cleaning electronic circuit boards at the bench. Results of our investigation will be documented in a written report.

\section{Key Assumptions}

Based on previous experience with research of this type, these are reasonable personnel and time expenditures. It is necessary to review the literature so as not to reinvent the wheel. It will take some time to order, review, and digest the previous work and access the applicability. Ordering the chemicals will involve interfacing with suppliers who produce suitable materials and who have had experience with cleaners suitable for this application. The chemicals will be sorted and cataloged according to chemical, physical properties, and safety/health considerations. Evaluation will require training in proper soldering and cleaning techniques and criteria for judging circuit board cleanness. A series of soldered uncleaned boards will be created and used to evaluate cleaner effectiveness. Things to be considered will be safety, residue, cleanliness, odor, etc.

The data which is generated will be evaluated against requirements to choose adequate candidates or to select new ones. The data and conclusions will be documented in a final report. 